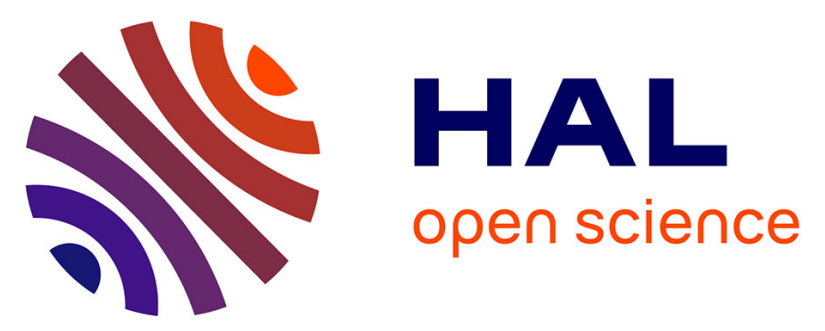

\title{
Equilibrium constants in aqueous lanthanide and actinide chemistry from time-resolved fluorescence spectroscopy: The role of ground and excited state reactions
}

Isabelle Billard, Klaus Lützenkirchen

\section{To cite this version:}

Isabelle Billard, Klaus Lützenkirchen. Equilibrium constants in aqueous lanthanide and actinide chemistry from time-resolved fluorescence spectroscopy: The role of ground and excited state reactions. Radiochimica Acta, 2003, 91 (5), pp.285 - 294. 10.1524/ract.91.5.285.20314 . hal-02271941

\section{HAL Id: hal-02271941 \\ https://hal.science/hal-02271941}

Submitted on 27 Aug 2019

HAL is a multi-disciplinary open access archive for the deposit and dissemination of scientific research documents, whether they are published or not. The documents may come from teaching and research institutions in France or abroad, or from public or private research centers.
L'archive ouverte pluridisciplinaire HAL, est destinée au dépôt et à la diffusion de documents scientifiques de niveau recherche, publiés ou non, émanant des établissements d'enseignement et de recherche français ou étrangers, des laboratoires publics ou privés. 


\title{
Equilibrium constants in aqueous lanthanide and actinide chemistry from time-resolved fluorescence spectroscopy: The role of ground and excited state reactions
}

\author{
By Isabelle Billard* and Klaus Lützenkirchen ${ }^{1}$ \\ Institut de Recherches Subatomiques, Chimie Nucléaire, CNRS/IN2P3 and Université Louis Pasteur, F-67037 Strasbourg Cedex 2, France
}

(Received July 19, 2002; accepted in revised form October 16, 2002)

\section{Fluorescence /U(VI) / Lanthanides(III) / Cm(III) / \\ Equilibirium constant}

Summary. Equilibrium constants for aqueous reactions between lanthanide or actinide ions and (in-) organic ligands contain important information for various radiochemical problems, such as nuclear reprocessing or the migration of radioelements in the geosphere. We study the conditions required to determine equilibrium constants by time-resolved fluorescence spectroscopy measurements. Based on a simulation study it is shown that the possibility to determine equilibrium constants depends upon the reaction rates in the photoexcited states of the lanthanide or actinide ions.

\section{Introduction}

The measurement of rate constants in equilibrium reactions is a crucial aspect in lanthanide and actinide chemsitry. Such rate constants, usually measured in aqueous systems and involving complexing inorganic or organic ligands, are required to predict the transport behaviour of the elements in the environment and for safety assessment studies of nuclear waste repositories $[1,2]$. Several techniques are available for the determination of equilibrium reaction rate constants, such as potentiometry [3], solvent extraction [4-6], spectrophotometry [6-8] and electrospray mass-spectrometry $[9,10]$ or, in the case of fluorescent ions, Time-Resolved Laser-induced Fluorescence Spectroscopy (TRLFS) [11-14]. This last technique allow quantitative measurements of very dilute solutions down to concentrations of $5 \times 10^{-13} \mathrm{M}$ in the case of $\mathrm{Cm}^{3+}$ [12]. This facilitates considerably the handling of highly radioactive materials and allows to study speciation under environmental conditions. When applied to radiochemical problems, TRLFS is more or less restricted to solutions of U(VI) [15-22], Cm(III) [23-29] and various lanthanide(III) elements [30-38]. Among these, Eu(III) is the most commonly used one, as it is considered a good homologue of

\footnotetext{
*Author for correspondence

(E-mail: isabelle.billard@ires.in2p3.fr).

${ }^{1}$ Present address: Institute for Transuranium Elements, Joint Research Centre, European Commission, P.O. Box 2340, D-76125 Karlsruhe, Germany
}

the trivalent oxidation state of actinides, particularly Am(III) and $\mathrm{Cm}(\mathrm{III})$. TRLFS is also a well-established technique in the case of reaction studies of fluorescent lanthanides with organic ligands [39, 40].

The determination of equilibrium constants from TRLFS data was first described for the europium case [41, 42]. Several scenarios, i.e. fast and slow photochemical reactions, were discussed in [41] which allow one to deduce equilibrium constants based on TRLFS. In more recent years, the method has in particular been applied for actinide elements [18, 23, 28, 43]. However, the assumptions made in the analysis of the lanthanide case $[41,42]$ might not be valid for actinides. In fact, discrepancies appear between some studies when equilibrium reaction rate constants determined with TRLFS and other techniques are compared. Equilibrium constants differ, for example, by a factor of 7 for $\mathrm{Cm}^{3+} / \mathrm{F}^{-}$[23], a factor of about 30 (depending on the ionic strength) for $\mathrm{Cm}^{3+} / \mathrm{Cl}^{-}$[44], and a factor of 3 for $\mathrm{Cm}^{3+} / \mathrm{OH}^{-}$[29] and for $\mathrm{Cm} / \mathrm{SO}_{4}{ }^{2-}$ [44]. In other cases, however, the agreement between various methods is $\operatorname{good}\left(\right.$ e.g., the systems $\mathrm{UO}_{2}{ }^{2+} / \mathrm{PO}_{4}{ }^{3-}, \mathrm{UO}_{2}{ }^{2+} / \mathrm{SO}_{4}{ }^{2-}$ or $\left.\mathrm{UO}_{2}{ }^{2+} / \mathrm{NO}_{3}{ }^{-}[16,18,45]\right)$. This raises the question of the applicability of the TRLFS method for elements other than lanthanides.

In this contribution we first discuss the general scheme of chemical equations needed to describe a TRLFS experiment as well as a simplified model without photophysical reactions. In both cases, expressions for the equilibrium constants are given for a $1: 1$ complexation reaction in solution as well as the relationship between the two values. Based on previous work $[18,46]$ we then study the uranyl and europium cases in more detail. With the help of simulations, the conditions to derive equilibrium constants from TRLFS data are worked out.

\section{Complexation reactions involving laser excitation}

A solution is supposed to contain two species, M and L, which form a $1: 1$ complex. The general reaction scheme after pulsed laser excitation of $\mathbf{M}$ can be described as follows: 


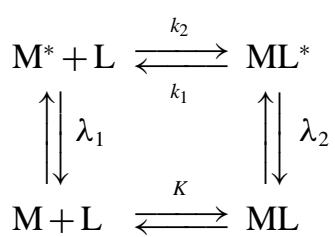

$K$ is the equilibrium reaction rate constant in the ground state, $k_{1,2}$ are the reaction rate constants in the excited state and $\lambda_{1,2}$ are the intrinsic fluorescence decay rates of $\mathrm{M}^{*}$ and $\mathrm{ML}^{*}$.

In this scheme, $\mathbf{M}$ is the fluorescent probe and it is assumed that complexation, although modifying the electronic configuration of $\mathrm{M}$, still allows for fluorescence to occur. In contrast, $\mathrm{L}$ is assumed not to absorb at the excitation wavelength. A typical experiment consists in measuring time-resolved emission spectra as a function of the ligand concentration up to a large excess with respect to the concentration of the metal ion.

Scheme (I) has been used to derive rate constants $k_{1}$ and $k_{2}$ between excited species for various systems of interest in photophysics [47-53]. For those cases where only groundstate chemistry is involved, simple relationships are well known between the amplitudes of the emission spectra and the concentrations of the ground-state species. Also, the observed lifetimes are known to represent the distinct decay rates of the non-interacting excited species. In contrast, in the case of excited state reactions (which is the case examined in the above cited references), it is clear that neither of these simple relationships exist so that no information can be obtained on the $K$ value in this case [54].

This scheme has also been discussed for europium in two independant studies $[41,42]$. One of the questions raised is under which conditions scheme (I), which leads to rather complicated rate equations, can be approximated by the following simpler model which neglects excited state reactions:

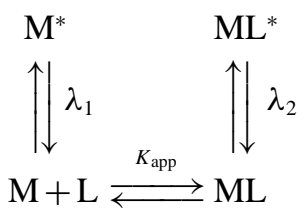

$K_{\text {app }}$ stands for the apparent equilibrium rate constant. In the following, expressions for the equilibrium constants $K$ and $K_{\text {app }}$ will be derived in order to verify, whether or not $K_{\text {app }}$ is a good approximation to the constant $K$ in scheme (I). Scheme (I) and model (II) will be treated in parallel in order to facilitate the comparison.

The equilibrium between the ground state species is given by:

$$
K=\frac{[\mathrm{ML}]}{[\mathrm{M}][\mathrm{L}]}, \quad \text { for scheme (I). }
$$

Expressions in square brackets denote activities. Eq. (1) is also valid once the laser beam has created the excited species $\mathrm{M}^{*}$ and $\mathrm{ML}^{*}$, as it will be assumed that all excited concentrations are far below the ground-state ones. The equilibrium constant in the excited state is:

$$
K^{*}=\frac{k_{2}}{k_{1}}=\frac{\left[\mathrm{ML}^{*}(t)\right]}{\left[\mathrm{M}^{*}(t)\right][\mathrm{L}]} .
$$

The time dependencies of $\mathrm{M}^{*}$ and $\mathrm{ML}^{*}$ follow from scheme (I) and model (II):
Scheme I

$$
\begin{aligned}
& \frac{\mathrm{d}\left[\mathrm{M}^{*}(t)\right]}{\mathrm{d} t}=-\left\{\lambda_{1}+k_{2}[\mathrm{~L}]\right\}\left[\mathrm{M}^{*}(t)\right]+k_{1}\left[\mathrm{ML}^{*}(t)\right], \\
& \frac{\mathrm{d}\left[\mathrm{ML}^{*}(t)\right]}{\mathrm{d} t}=-\left\{\lambda_{2}+k_{1}\right\}\left[\mathrm{ML}^{*}(t)\right]+k_{2}[\mathrm{~L}]\left[\mathrm{M}^{*}(t)\right] .
\end{aligned}
$$

\section{Model II}

$$
\begin{aligned}
& \frac{\mathrm{d}\left[\mathrm{M}^{*}(t)\right]}{\mathrm{d} t}=-\lambda_{1}\left[\mathrm{M}^{*}(t)\right], \\
& \frac{\mathrm{d}\left[\mathrm{ML}^{*}(t)\right]}{\mathrm{d} t}=-\lambda_{2}\left[\mathrm{ML}^{*}(t)\right] .
\end{aligned}
$$

Upon integration one obtains:

\section{$\underline{\text { Scheme I }}$}

$\left[\mathrm{M}^{*}(t)\right]=A \exp \left(\Lambda_{1} t\right)+B \exp \left(\Lambda_{2} t\right)$,

$\left[\mathrm{ML}^{*}(t)\right]=C \exp \left(\Lambda_{1} t\right)+D \exp \left(\Lambda_{2} t\right)$.

Model II

$$
\begin{aligned}
& {\left[\mathrm{M}^{*}(t)\right]=\left[\mathrm{M}^{*}(0)\right] \exp \left(-\lambda_{1} t\right),} \\
& {\left[\mathrm{ML}^{*}(t)\right]=\left[\mathrm{ML}^{*}(0)\right] \exp \left(-\lambda_{2} t\right) .}
\end{aligned}
$$

$\Lambda_{1}$ and $\Lambda_{2}$ have negative values and are given by the roots of a second order polynomial:

$$
\begin{aligned}
\Lambda_{1,2}= & -\frac{1}{2}\left(\lambda_{1}+\lambda_{2}+k_{2}[\mathrm{~L}]+k_{1}\right) \\
& \pm \sqrt{\left\{\begin{array}{l}
\left(\lambda_{1}+\lambda_{2}+k_{2}[\mathrm{~L}]+k_{1}\right)^{2} \\
\left.-4\left[\left(\lambda_{2}+k_{1}\right)\left(\lambda_{1}+k_{2}[\mathrm{~L}]\right)-k_{1} k_{2}\right]\right\}
\end{array}\right.} .
\end{aligned}
$$

In Eq. (5), $\Lambda_{1}$ is obtained for the positive sign and $\Lambda_{2}$ for the negative sign before the square root.

For scheme (I), the decay spectrum, i.e. the time dependence of the sum of $\mathrm{M}^{*}$ and $\mathrm{ML}^{*}$, contains two decaying channels that cannot be identified with the two fluorescing moieties $\mathbf{M}^{*}$ and $\mathrm{ML}^{*}$ : the two excited species both decay with two different lifetime values, $\left(-1 / \Lambda_{1}\right)$ and $\left(-1 / \Lambda_{2}\right)$, that are a function of [L]. In contrast, in the case of model (II), each decaying species is characterized by its own lifetime, $\lambda_{1}^{-1}$ or $\lambda_{2}^{-1}$, both independent of [L].

The intensities $I_{i}^{\mathrm{I}}$ and $I_{i}^{\mathrm{II}}$ associated with the channels $\left(-1 / \Lambda_{i}\right)$ and $\lambda_{i}^{-1}$, respectively, can be written as:

\section{$\underline{\text { Scheme I }}$}

$$
\begin{aligned}
& I_{1}^{\mathrm{I}}=\int_{0}^{+\infty}\left[k_{\mathrm{rad}, 1} A \exp \left(\Lambda_{1} t\right)+k_{\mathrm{rad}, 2} C \exp \left(\Lambda_{1} t\right)\right] \mathrm{d} t, \\
& I_{2}^{\mathrm{I}}=\int_{0}^{+\infty}\left[k_{\mathrm{rad}, 1} B \exp \left(\Lambda_{2} t\right)+k_{\mathrm{rad}, 2} D \exp \left(\Lambda_{2} t\right)\right] \mathrm{d} t,
\end{aligned}
$$

$\underline{\text { Model II }}$

$$
\begin{aligned}
I_{1}^{\mathrm{II}} & =\int_{0}^{+\infty} k_{\mathrm{rad}, 1}\left[\mathrm{M}^{*}(0)\right] \exp \left(-\lambda_{1} t\right) \mathrm{d} t, \\
I_{2}^{\mathrm{II}} & =\int_{0}^{+\infty} k_{\mathrm{rad}, 2}\left[\mathrm{ML}^{*}(0)\right] \exp \left(-\lambda_{2} t\right) \mathrm{d} t,
\end{aligned}
$$


where $k_{\mathrm{rad}, i}$ is the radiative part of the total decay rate:

$$
\lambda_{i}=k_{\mathrm{rad}, i}+k_{\mathrm{nonrad}, i} .
$$

By defining $\rho_{i}$ as the fluorescence quantum yields:

$$
\rho_{i}=\frac{k_{\mathrm{rad}, i}}{k_{\mathrm{rad}, i}+k_{\mathrm{nonrad}, i}}
$$

and $\alpha$ and $\beta$ as the absorption coefficients:

$$
\begin{aligned}
& {\left[\mathrm{M}^{*}(0)\right]=\alpha[\mathrm{M}],} \\
& {\left[\mathrm{ML}^{*}(0)\right]=\beta[\mathrm{ML}],}
\end{aligned}
$$

one obtains after integration:

\section{Scheme I}

$$
\begin{aligned}
& I_{1}^{\mathrm{I}}=\frac{-\left(A k_{\mathrm{rad}, 1}+C k_{\mathrm{rad}, 2}\right)}{\Lambda_{1}}, \\
& I_{2}^{\mathrm{I}}=\frac{-\left(B k_{\mathrm{rad}, 1}+D k_{\mathrm{rad}, 2}\right)}{\Lambda_{2}} .
\end{aligned}
$$

$\underline{\text { Model II }}$

$$
\begin{aligned}
& I_{1}^{\mathrm{II}}=\frac{k_{\mathrm{rad}, 1} \alpha[\mathrm{M}]}{\lambda_{1}}=\rho_{1} \alpha[\mathrm{M}], \\
& I_{2}^{\mathrm{II}}=\frac{k_{\mathrm{rad}, 2} \beta[\mathrm{ML}]}{\lambda_{2}}=\rho_{2} \beta[\mathrm{ML}] .
\end{aligned}
$$

The expressions for $A, B, C$ and $D$ are obtained from Eqs. (3), (4) and (8):

$$
\begin{aligned}
A & =\frac{\alpha\left[\mathrm{M}^{*}(0)\right]\left[\Lambda_{2}+\lambda_{1}+k_{2}[\mathrm{~L}]\right]-k_{1} \beta\left[\mathrm{ML}^{*}(0)\right]}{\left(\Lambda_{2}-\Lambda_{1}\right)}, \\
B & =\alpha\left[\mathrm{M}^{*}(0)\right]-A, \\
C & =\frac{\Lambda_{1}+\lambda_{1}+k_{2}[\mathrm{~L}]}{k_{1}} A, \\
D & =\beta\left[\mathrm{ML}^{*}(0)\right]-C .
\end{aligned}
$$

Similarly, the intensities $J_{i}^{\mathrm{I}}$ and $J_{i}^{\mathrm{II}}$ associated to the emitting species $\mathrm{M}^{*}$ and $\mathrm{ML}^{*}$, respectively, can be calculated as:

\section{Scheme I}

$$
\begin{aligned}
& J_{1}^{\mathrm{I}}=\int_{0}^{+\infty} k_{\mathrm{rad}, 1}\left[A \exp \left(\Lambda_{1} t\right)+B \exp \left(\Lambda_{2} t\right)\right] \mathrm{d} t, \\
& J_{2}^{\mathrm{I}}=\int_{0}^{+\infty} k_{\mathrm{rad}, 2}\left[C \exp \left(\Lambda_{1} t\right)+D \exp \left(\Lambda_{2} t\right)\right] \mathrm{d} t .
\end{aligned}
$$

\section{$\underline{\text { Model II }}$}

$$
\begin{aligned}
& J_{1}^{\mathrm{II}}=\int_{0}^{+\infty} k_{\mathrm{rad}, 1}\left[\mathrm{M}^{*}(0)\right] \exp \left(-\lambda_{1} t\right) \mathrm{d} t, \\
& J_{2}^{\mathrm{II}}=\int_{0}^{+\infty} k_{\mathrm{rad}, 2}\left[\mathrm{ML}^{*}(0)\right] \exp \left(-\lambda_{2} t\right) \mathrm{d} t .
\end{aligned}
$$

$\underline{\text { Scheme I }}$

$$
\begin{aligned}
& J_{1}^{\mathrm{I}}=-\frac{A k_{\mathrm{rad}, 1}}{\Lambda_{1}}-\frac{B k_{\mathrm{rad}, 1}}{\Lambda_{2}}, \\
& J_{2}^{\mathrm{I}}=-\frac{C k_{\mathrm{rad}, 2}}{\Lambda_{1}}-\frac{D k_{\mathrm{rad}, 2}}{\Lambda_{2}} .
\end{aligned}
$$

\section{Model II}

$$
\begin{aligned}
& J_{1}^{\mathrm{II}}=\frac{k_{\mathrm{rad}, 1} \alpha[\mathrm{M}]}{\lambda_{1}}=\rho_{1} \alpha[\mathrm{M}], \\
& J_{2}^{\mathrm{II}}=\frac{k_{\mathrm{rad}, 2} \beta[\mathrm{ML}]}{\lambda_{2}}=\rho_{2} \beta[\mathrm{ML}] .
\end{aligned}
$$

$J_{1}^{\mathrm{I}}$ and $J_{2}^{\mathrm{I}}$ contain the terms $k_{\mathrm{rad}, 1}$ and $k_{\mathrm{rad}, 2}$, in contrast with the expressions derived in [41] which only contain the terms $\lambda_{i}$. The inclusion of $k_{\mathrm{rad}, i}$ appears reasonnable, since the radiative part (cf. Eq. (6)) determines the contribution of species $i$ to the experimental emission spectrum.

Within scheme (I), each one of the emitting species decays with two rate constants (cf. Eq. (4)). Therefore, the expressions of the $I_{i}^{\mathrm{I}}$ differ from those of the $J_{i}^{\mathrm{I}}$. For model (II), on the other hand, the expressions for $I_{i}^{\mathrm{II}}$ and $J_{i}^{\mathrm{II}}$ are identical, since each one of the species has a unique decay rate (cf. Eq. $\left(4^{\prime}\right)$ ). However, within both scheme (I) and model (II), $\mathrm{M}^{*}$ and $\mathrm{ML}^{*}$ have their proper emission spectrum. In other words, the total emission spectrum is the weighted sum of the individual contributions (either $J_{i}^{\mathrm{I}}-$ scheme (I) - or $J_{i}^{\mathrm{II}}-$ model (II)) of the two emitting species.

To summarize for scheme (I), the $I_{i}^{\mathrm{I}}$ values represent the intensities of the decay spectra, whereas the $J_{i}^{\mathrm{I}}$ values represent the intensities of the emission spectra. Therefore, the emitting species $\mathrm{M}^{*}$ and $\mathrm{ML}^{*}$ can in principle be identified from an unfolding procedure of the total emission spectrum, and thus experiments are mainly based on the evaluation of emission rather than decay spectra. Nevertheless, it is clear that some physical information is also contained in the decay spectra and the derived lifetimes. This issue will be outlined below (see Sects. 4 and 5).

Finally, it is possible to calculate the fluorescence ratio, $R_{\text {fluo }}=J_{2} / J_{1}$. It corresponds to the intensity ratio of solutions containing either only $\mathrm{M}^{*}$ or $\mathrm{ML}^{*}$ :

$\underline{\text { Scheme I }}$

$$
R_{\text {fluo }}=\frac{J_{2}^{\mathrm{I}} \text { for }[\mathrm{L}]=\infty}{J_{1}^{\mathrm{I}} \text { for }[\mathrm{L}]=0} .
$$

\section{$\underline{\text { Model II }}$}

$$
R_{\text {fluo }}=\frac{J_{2}^{\mathrm{II}} \text { for }[\mathrm{L}]=\infty}{J_{1}^{\mathrm{II}} \text { for }[\mathrm{L}]=0} \text {. }
$$

$\underline{\text { Scheme I }}$

$$
R_{\text {fluo }}=\frac{k_{\text {rad }, 2}\left[\frac{-C_{\infty}}{\Lambda_{1}}+\frac{-D_{\infty}}{\Lambda_{2}}\right]}{k_{\text {rad }, 1} \tau_{1} \alpha[\mathrm{M}]}=\frac{\tau_{2} k_{\text {rad }, 2}}{\tau_{1} k_{\text {rad }, 1}} \frac{\beta}{\alpha} .
$$

$\underline{\text { Model II }}$

$$
R_{\text {fluo }}=\frac{\tau_{2} k_{\text {rad }, 2}}{\tau_{1} k_{\text {rad }, 1}} \frac{\beta}{\alpha}=\frac{\rho_{2} \beta}{\rho_{1} \alpha} .
$$

$C_{\infty}$ and $D_{\infty}$ are calculated for an infinitely large concentration of L. Experimentally, $R_{\text {fluo }}$ is obtained by dividing the total signal intensity of a solution with given $[\mathrm{M}]$ plus 
a large excess of L by the total signal intensity of a solution containing only $\mathrm{M}$, at the same concentration as previously. Eqs. $\left(11,11^{\prime}\right)$ for $R_{\text {fluo }}$ are identical because $R_{\text {fluo }}$ is an experimental and model-independant parameter. Eq. (11') can also be obtained by the following simple reasonning: $R_{\text {fluo }}$ must be proportional to the ratio of the fluorescence quantum yields of the species. This factor is an intrinsic property of the species $\mathrm{M}^{*}$ and $\mathrm{ML}^{*}$ in a given solvent. Secondly, $R_{\text {fluo }}$ depends upon the relative amounts of species $\mathrm{M}^{*}$ and $\mathrm{ML}^{*}$ which are proportional to the absorption coefficients $\alpha$ and $\beta$ (see Eq. (9)).

We now address the question of modeling experimental emission spectra with model (II). As explained above, $R_{\text {fluo }}$ can be determined from two independent measurements. Therefore, the experimental emission spectrum can be decomposed into two contributions. These are fitted to Eqs. $\left(10^{\prime}\right)$, which can be written in relative terms:

$$
\begin{aligned}
J_{1, \text { rel }}^{\mathrm{II}} & =\frac{J_{1}^{\mathrm{II}}}{J_{1}^{\mathrm{II}}+J_{2}^{\mathrm{II}}}=\frac{1}{1+\frac{\rho_{2} \beta}{\rho_{1} \alpha} \frac{[\mathrm{ML}]}{[\mathrm{M}]}}=\frac{1}{1+\frac{\rho_{2} \beta}{\rho_{1} \alpha}[\mathrm{L}] K_{\text {app }}} \\
& =\frac{1}{1+R_{\text {fluo }}[\mathrm{L}] K_{\text {app }}}, \\
J_{2, \text { rel }}^{\mathrm{II}} & =1-J_{1, \text { rel }}^{\mathrm{II}} .
\end{aligned}
$$

The equilibrium concentration $[\mathrm{L}]$ is a function of the initial concentrations $[\mathrm{M}]_{0}$ and $[\mathrm{L}]_{0}$ as well as of $K_{\text {app }}$, which is thus the only unknown parameter of Eq. $\left(12^{\prime}\right)$. As is obvious from Eqs. (3), (3') to (10), (10'), scheme (I) and model (II) lead to very different expressions for the various quantities discussed. This raises the question as to whether model (II) can be considered a reasonable approximation of the more complex scheme (I). This point is discussed qualitatively in the next section. In the subsequent section, the same issue is treated quantitatively with the help of simulations.

\section{Approximation of scheme (I) by use of model (II): a qualitative approach}

\subsection{Regime A: photochemistry is negligible}

If reactions in the excited state are negligible, i.e., for $k_{1}$ and $k_{2}[\mathrm{~L}] \ll \lambda_{1,2}$, no significant mixing occurs before the majority of excited species has decayed to their respective ground states. Model (II) is a good approximation of scheme (I) and one obtains, in agreement with $[41,42]$ :

$$
K_{\text {app }}=K \text {. }
$$

\subsection{Regime B: photochemistry is neither negligible nor dominating}

Model (II) is not expected to be a good approximation of scheme (I) if $k_{1}$ and $k_{2}[\mathrm{~L}] \approx \lambda_{1,2}$. Again, this qualitative result is in agreement with a previous study [41], even though the quantitative results differ (Eq. (10)), as already stressed.

\subsection{Regime $\mathrm{C}$ : photochemistry is the dominating process}

The third case corresponds to rapid photochemical processes, where the equilibrium between the excited species is attained before a significant amount has decayed. This scenario differs considerably from the physical basis of model (II). In view of its simplicity, a fit of experimental emission spectra by use of model (II) might, however, still be attractive. The question remains as to the relationship between the derived $K_{\text {app }}$ value and the various parameters of the kinetic scheme (I). In the following, we will derive an expression of $K_{\text {app }}$ based on qualitative arguments which take into account light absorption, installation of equilibrium and decay to the ground-state:

i) The quantities of $\mathrm{M}^{*}$ and $\mathrm{ML}^{*}$ generated by laser excitation depend upon the equilibrium constant $K$ and the photoabsorption coefficients $\alpha$ and $\beta$. The information on $K$ which is contained in the values $\left[\mathrm{M}^{*}(0)\right]$ and $\left[\mathrm{ML}^{*}(0)\right]$ is lost due to the rapid photochemical processes $\left(k_{1,2} \gg \lambda_{1,2}\right)$. These lead to new values of $\mathrm{M}^{*}$ and $\mathrm{ML}^{*}$ quasi instantaneously. Therefore, the measured equilibrium constant $K_{\text {app }}$ is proportional to $K^{*}$. ii) For given values of $K$ and $K^{*}$, an increase in $\alpha$ (all other parameters constant) will create more $\left[\mathrm{M}^{*}(0)\right]$. This, in turn, will lead to an increasing complexation. Reversely, an increase in $\beta$ will induce an enhanced dissociation of $\mathrm{ML}^{*}$. Therefore, $K_{\text {app }}$ is proportional to the ratio $(\alpha / \beta)$. iii) The time dependence of $\left[\mathrm{M}^{*}\right]$ and $\left[\mathrm{ML}^{*}\right]$ is governed by two processes, the depletion by deexcitation $\left(\lambda_{1}\right.$ and $\left.\lambda_{2}\right)$ and the equilibrium reaction $\left(K^{*}=k_{2} / k_{1}\right)$. Assuming $\lambda_{1}>\lambda_{2}$, which is generally the case, deexcitation occurs predominantly via the channel $\mathrm{M}^{*} \rightarrow \mathrm{M}$. Thus, more photons come from the $\mathrm{M}^{*}$ decay than expected if no mixing would occur. With these considerations in mind, model (II) can be regarded as an approximation of scheme (I) with the following expression of $K_{\text {app }}$ :

$$
K_{\text {app }}=K^{*} \frac{\alpha}{\beta} \frac{\tau_{1}}{\tau_{2}} .
$$

This qualitative result can be applied to any fluorescent chemical system. It differs from the relation proposed in [41] which does not include the term $(\alpha / \beta)\left(\tau_{1} / \tau_{2}\right)$.

In the case of lanthanides, the $4 f$ electrons, which are involved in the photoexcitation process, are strongly shielded. Hence one may assume that:

$$
K^{*} \approx K .
$$

This yields:

$$
K_{\text {app }} \approx K \frac{\alpha}{\beta} \frac{\tau_{1}}{\tau_{2}} .
$$

It has to be noted that Eq. (14) is an approximation which is valid for lanthanide elements. This is not necessarily the case for actinides or other elements. In the following section we will go beyond the qualitative arguments and present simulations of the three photophysical regimes discussed until now.

\section{Approximation of scheme (I) by use of model (II): a simulation study}

\subsection{Conditions of the simulation study}

We will first discuss the influence of excited state reactions on the lifetimes of the decay channels $\left(-1 / \Lambda_{i}\right)$ and on the 
emission intensities $J_{i}^{\mathrm{I}}$ of the excited species. Subsequently, the feasability of approximating scheme (I) by model (II) will be investigated mainly for the case of fast excited state reactions.

As is obvious from Sect. 2, scheme (I) is based on a considerable number of parameters. A complete study of the influence of all the parameters is out of the scope of this work and the simulations are restricted to the effects of the excited state rate constants $k_{1}$ and $k_{2}$. The choice of two different systems allows to illustrate the influence of some of the other parameters $\left(\lambda_{1}, \lambda_{2}\right.$ and $\left.\alpha / \beta\right)$.

The three photochemical regimes are characterized as follows: negligible photochemical processes (regime A) are assumed to result in experimental lifetime values $\left(-1 / \Lambda_{1}\right.$ and $-1 / \Lambda_{2}$ ) which do not vary by more than $5 \%$ over the total range of ligand concentrations. This corresponds to the typical uncertainty of TRLFS measurements. In regime A, the decays are biexponential, which can be verified by examination of the residuals.

In regime $\mathrm{B}$, photochemical processes are not fast enough to fully mix the two excited states. However, their influence on the apparent lifetimes $\left(-1 / \Lambda_{1}\right)$ and $\left(-1 / \Lambda_{2}\right)$ cannot be neglected. The decay spectrum remains biexponential, as for regime $\mathrm{A}$, but the lifetimes vary as a function of $[\mathrm{L}]$ (see Eq. (5)). Both lifetimes are supposed to be above $1 \mu$ s, which corresponds to the usual time-resolution of TRLFS systems used for radiochemical complexation studies. In both regimes the decay spectra are biexponential. However, in regime $\mathrm{A}$, the lifetimes are independent of the ligand concentration, whereas in regime B they are not. The important point is that the two regimes $\mathrm{A}$ and $\mathrm{B}$ can be distinguished by a close examination of the decay spectra, not of the emission spectra.

In the case of regime $\mathrm{C}$, it is well known [55] that the two decaying species cannot be distinguished via the lifetimes: one of the two lifetimes $\left(-1 / \Lambda_{1}\right.$ and $\left.-1 / \Lambda_{2}\right)$ is very short $(<1 \mu \mathrm{s})$ while its associated intensity, $I_{i}^{\mathrm{I}}$, tends to zero. The decay spectra appear therefore monoexponential and this can be easily checked by examination of the residuals. Note that in this case the monoexponential behaviour is not an indication of the presence of a single species in solution but of a fast mixing of at least two species. The regimes A, $\mathrm{B}$ and $\mathrm{C}$ can thus be distinguished by a close examination of the decay spectra. No information in that respect can be extracted from the emission spectra.

Two systems of interest to radiochemical problems have been chosen as model cases, i.e., $\mathrm{UO}_{2}{ }^{2+} / \mathrm{SO}_{4}{ }^{2-}$ and $\mathrm{Eu}(\mathrm{III}) /$ carboxylate. Some parameter values needed for the simulation study were taken from published data, other values were defined within a physically reasonable range. For the two systems, the values of $k_{\text {rad, } i}$ were chosen within the constraints given by Eqs. (6) and (11). Table 1 shows all parameter values that are used in the simulation study.

The actinide case is represented by the system $\mathrm{UO}_{2}{ }^{2+} /$ $\mathrm{SO}_{4}{ }^{2-}$ which has been well characterized in a number of studies [56]. The TRLFS work of Geipel et al. [18] provides most of the experimental values needed for the simulations. The value $(\alpha / \beta)$, (see Table 1), was estimated experimentally from the absorption spectra of two solutions measured at $\lambda_{\text {exc }}=270 \mathrm{~nm}$, which is the wavelength used in [18]: i) $\left(\mathrm{UO}_{2}{ }^{2+}\right)_{\mathrm{tot}}=10^{-2} \mathrm{M},\left(\mathrm{HClO}_{4}\right)=1 \mathrm{M}$ and ii) $\left(\mathrm{UO}_{2}{ }^{2+}\right)_{\mathrm{tot}}=$
Table 1. Values of the parameters used for the simulations.

\begin{tabular}{lcc}
\hline & Uranium case & Europium case \\
\hline$\tau_{1}(\mu \mathrm{s})$ & $2.7^{*}$ & $114.0^{*}$ \\
$\tau_{2}(\mu \mathrm{s})$ & $4.3^{*}$ & $119.0^{*}$ \\
$k_{\mathrm{rad}, 1}\left(\mu \mathrm{s}^{-1}\right)$ & $2.22 \times 10^{-3 a}$ & $4 \times 10^{-4 a}$ \\
$\tau_{\mathrm{r} 1}=1 / k_{\mathrm{rad}, 1}(\mu \mathrm{s})$ & 450 & 2500 \\
$k_{\mathrm{rad}, 2}\left(\mu \mathrm{s}^{-1}\right)$ & $2.80 \times 10^{-3 a}$ & $4 \times 10^{-4 a}$ \\
$\tau_{\mathrm{r} 2}=1 / k_{\mathrm{rad}, 2}(\mu \mathrm{s})$ & 357 & 2500 \\
$\alpha / \beta$ & $0.408^{b}$ & $0.909^{a}$ \\
$\log _{10} K$ & $3.15^{*}$ & $2.30^{a}$ \\
$K\left(\mathrm{M}^{-1}\right)$ & $1412^{*}$ & $200^{a}$ \\
$R_{\text {fluo }}$ & $4.90^{*}$ & $1.15^{a}$ \\
Metal concentration $(\mathrm{M})$ & $10^{-5 *}$ & $10^{-5 *}$ \\
Ligand range $(\mathrm{M})$ & 0 to $0.35^{*}$ & 0 to $5 \times 10^{-1 a}$ \\
\hline
\end{tabular}

*: as indicated in [18] (uranium case) or [46] (europium case);

a: arbitrarily fixed (see text)

b: from an experimental estimation (see text)

$10^{-2} \mathrm{M}, \mathrm{pH}=2,\left(\mathrm{SO}_{4}{ }^{2-}\right)_{\mathrm{tot}}=0.04 \mathrm{M}$. The ligand concentration is small in order to mainly produce the $1: 1$ complex which is the one studied in the simulation. Note that in the work of Geipel and coworkers, the maximum concentration of the $\mathrm{SO}_{4}{ }^{2-}$ ions was $0.35 \mathrm{M}$, which is needed to observe other complexes, such as $1: 2$ and $1: 3$.

For the lanthanide case, the system $\mathrm{Eu}(\mathrm{III}) /$ carboxylate has been selected because for some of the carboxylate anions the interaction is limited to the formation of the $1: 1$ complex [46]. A particular carboxylate anion was not chosen because the TRLFS study of [46] clearly shows that all these anions behave similarly. The simulations were performed by assuming that the ligand is always fully deprotonated. Unfortunately, as indicated in [46] the measurement of the absorption spectra of a solution containing the $1: 1$ complex alone is not possible due to the precipitation of the complex. The value $(\alpha / \beta)$ was therefore arbitrarily chosen to be close to one. This corresponds to the values known for various lanthanide complexes. The chosen value of the ground state equilibrium constant (see Table 1) is in the typical range for the anions of this series [46]. Finally, [46] does not indicate the value of $R_{\text {fluo }}$ for any of the carboxylate ions studied. For the simulation study, in order to make differences between the uranium and the europium case, a value close to 1 has been arbitrarily chosen (see Table 1). The range of ligand concentration examined has thus been chosen such that, for the given $K$, the relative concentration of the complex is about $100 \%$.

\subsection{Results of the simulations}

The three photochemical regimes are characterized by different values of excited state rate constants $k_{1}$ and $k_{2}$. The respective $k$-ranges for the uranium and europium system are shown in Figs. 1, 2. The dotted line in both figures corresponds to the limit above which the lifetime $\left(-1 / \Lambda_{1}\right)$ and its associated intensity value $\left(I_{1}^{\mathrm{I}}\right)$ are below $0.1 \mu \mathrm{s}$ and $0.1 \%$, respectively. The straight lines correspond to different values of $K^{*}$.

The values of $k_{1}$ and $k_{2}$ can cover the range between zero and the diffusion limit $\left(c a .10^{10} \mathrm{M}^{-1} \mathrm{~s}^{-1}\right.$ for $\left.k_{2}\right)$. Figs. 1, 2 show that the largest $k$-range is covered by zone C. From 


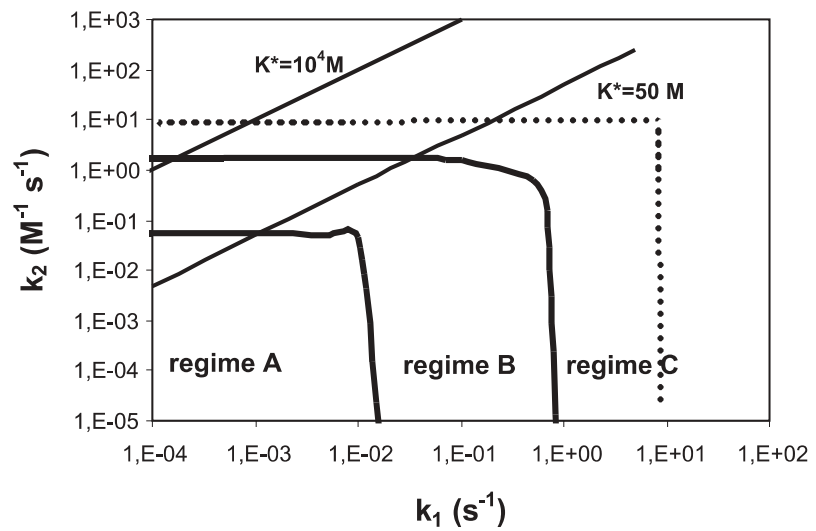

Fig. 1. Limits of the three regimes $\mathrm{A}, \mathrm{B}$ and $\mathrm{C}$ as a function of $k_{1}$ and $k_{2}$ for the uranium simulation case (solid curves). Dotted line: limit above which $\left(-1 / \Lambda_{1}\right)$ is below $0.1 \mu \mathrm{s}$. Straight lines: fixed values of $K^{*}$ (see text).

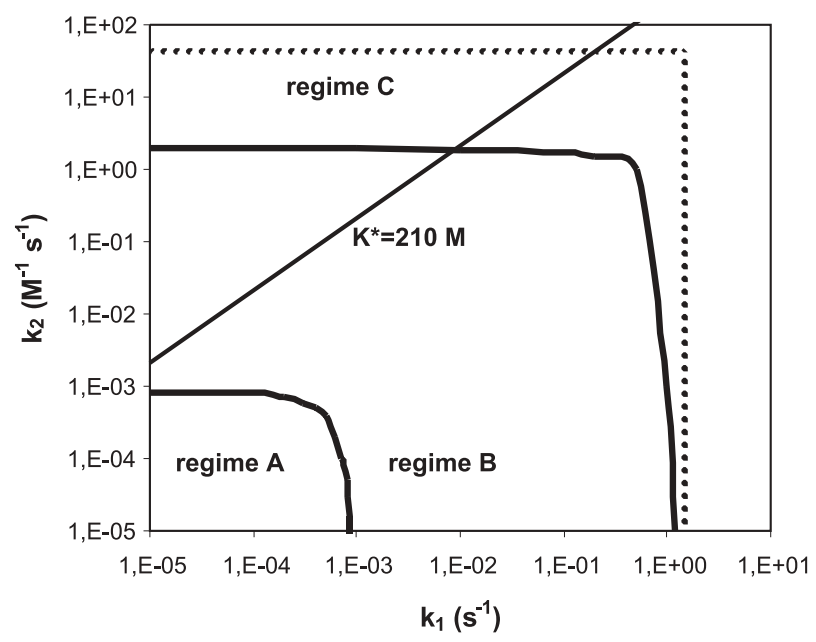

Fig. 2. Limits of the three regimes $\mathrm{A}, \mathrm{B}$ and $\mathrm{C}$ as a function of $k_{1}$ and $k_{2}$ for the europium simulation case (solid curves). Dotted line: limit above which $\left(-1 / \Lambda_{1}\right)$ is below $0.1 \mu$ s. Straight line: fixed value of $K^{*}$ (see text).

the figure, one can see that the role of $k_{1}$ and $k_{2}$ is symmetric: Above $k_{1} \approx 1 \mathrm{~s}^{-1}$, whatever the $k_{2}$ value, the system falls in regime $\mathrm{C}$ and, reversely, above $k_{2} \approx 5 \mathrm{M}^{-1} \mathrm{~s}^{-1}$, regime $\mathrm{C}$ is obtained whatever the $k_{1}$ value. This shows that the type of regime is not defined by $K^{*}$ but by the couple $\left(k_{1}, k_{2}\right)$. In particular, if the $k_{2}$ value is very near the diffusion limit, regime $\mathrm{C}$ is to be considered.

In a second step (see Figs. 3 to 6), the dependence of $\left(-1 / \Lambda_{1}\right)$ and $\left(-1 / \Lambda_{2}\right)$ on [L] was examined for several $k_{1}$-values representative of the three regimes. $K^{*}$-values were fixed, $K^{*}=50 \mathrm{M}$ for the uranium case and $K^{*}=$ $210 \mathrm{M}$ for the europium case. This latter value has been chosen close to the one of $K$ (see Table 1 and Eq. (14)). For the uranium case, $K^{*}<K$ (see Table 1) was chosen in order to take into account possible differences between $K^{*}$ and $K$ for actinides. Variations similar to those displayed in Figs. 3 to 6 were obtained for other $K^{*}$ values (not shown). The qualitative discussion on the ranges of the three regimes in the previous section emerges from the figures: In regime A (low $k_{1}$ values) the two lifetimes $\left(-1 / \Lambda_{1}\right)$ and $\left(-1 / \Lambda_{2}\right)$ do not vary significantly as a function of $[\mathrm{L}]$ while for the highest values of $k_{1}$ (zone C) $\left(-1 / \Lambda_{1}\right)$ is negligibly small. The

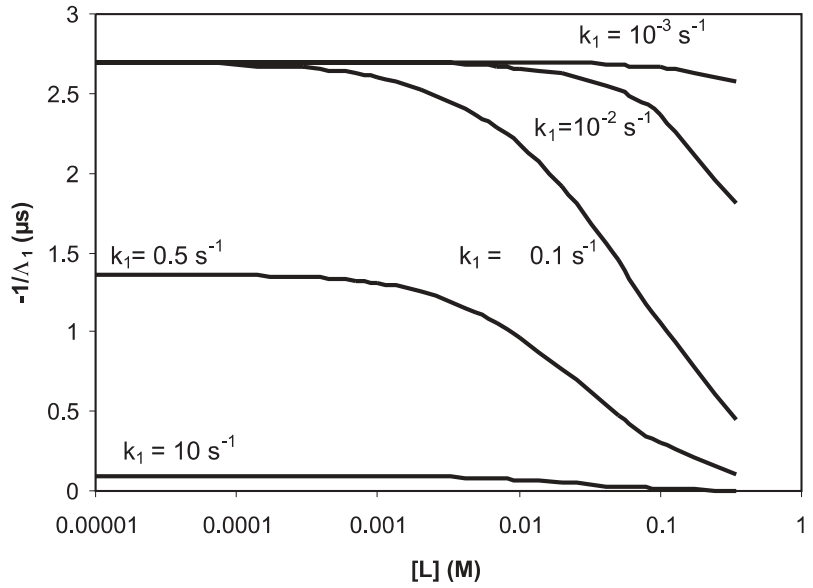

Fig. 3. Variation of $\left(-1 / \Lambda_{1}\right)$ as a function of [L] for different values of $k_{1}$ and a fixed value $K^{*}=50 \mathrm{M}$ for the uranium simulation case.

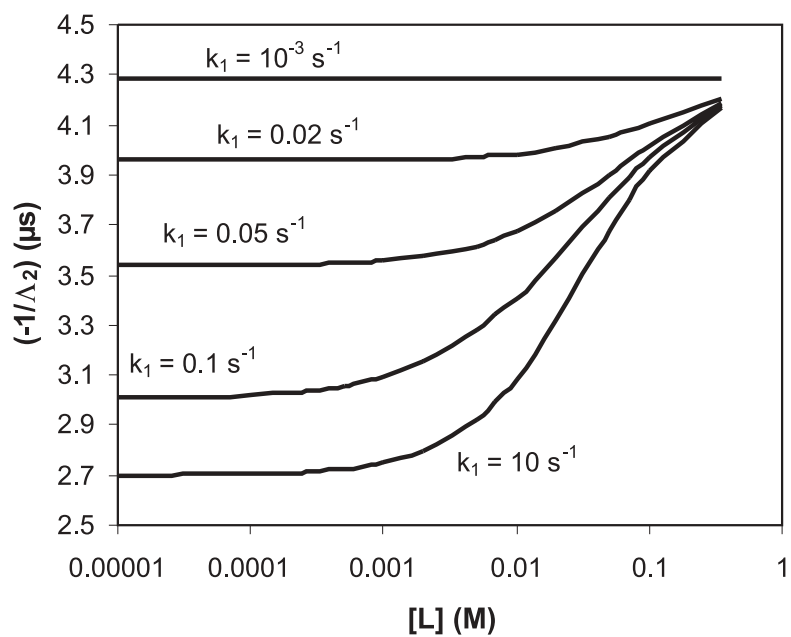

Fig. 4. Variation of $\left(-1 / \Lambda_{2}\right)$ as a function of [L] for different values of $k_{1}$ and a fixed value $K^{*}=50 \mathrm{M}$ for the uranium simulation case.

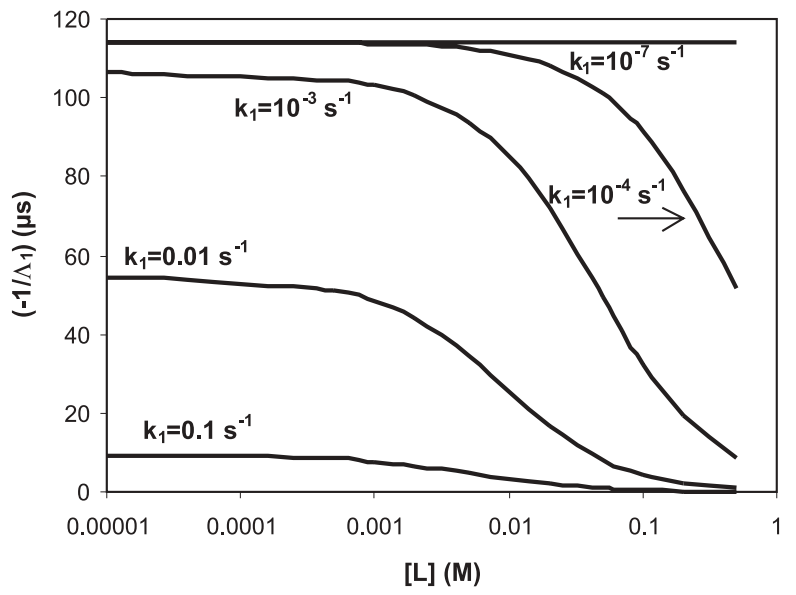

Fig. 5. Variation of $\left(-1 / \Lambda_{1}\right)$ as a function of [L] for different values of $k_{1}$ and a fixed value $K^{*}=210 \mathrm{M}$ for the europium simulation case.

decay spectrum thus contains only the $\left(-1 / \Lambda_{2}\right)$ component, the value of which varies from $\lambda_{1}^{-1}$ to $\lambda_{2}^{-1}$ as a function of [L]. Whatever the regime (i.e. the value of $k_{1}$ ) one of the two lifetimes $\left(-1 / \Lambda_{1}\right)$ or $\left(-1 / \Lambda_{2}\right)$ is equal to $\lambda_{1}^{-1}$ at $[\mathrm{L}]=0 \mathrm{M}\left(e . g ., \lambda_{1}^{-1}=\tau_{1}=2.7 \mu \mathrm{s}\right.$ in Figs. 3, 4). This is expected since $\lambda_{1}^{-1}$ is an experimental parameter that does not 


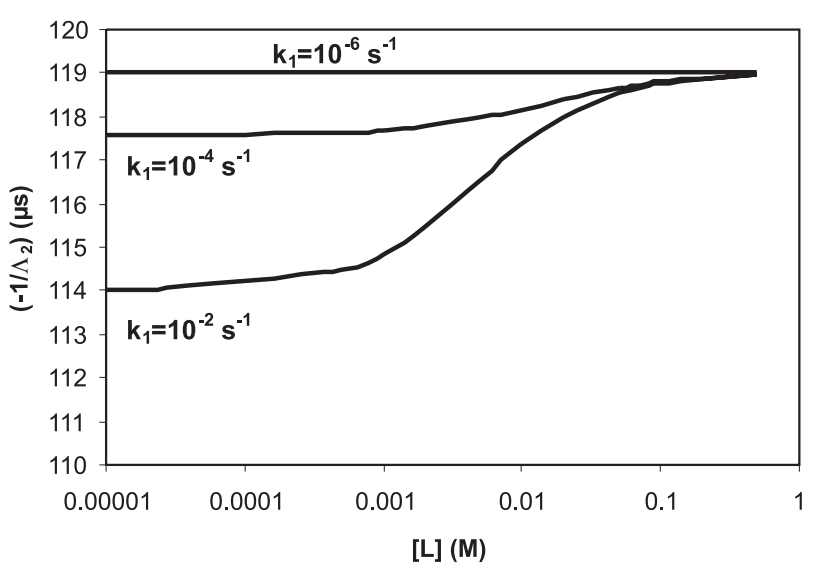

Fig. 6. Variation of $\left(-1 / \Lambda_{2}\right)$ as a function of [L] for different values of $k_{1}$ and a fixed value $K^{*}=210 \mathrm{M}$ for the europium simulation case.

depend on any model and can be determined independently for $[\mathrm{L}]=0 \mathrm{M}$. Note that for the uranium case in regime $\mathrm{C}$ $\left(k_{1}=10 \mathrm{~s}^{-1}\right)$, the observed lifetime $\left(-1 / \Lambda_{2}\right)$ is not exactly equal to $\lambda_{2}^{-1}(4.3 \mu \mathrm{s})$ for the maximun ligand concentration covered in this study (Fig. 4). This is clearly due to the fact that for $K^{*}=50 \mathrm{M}$ (conditions of the simulation), even for $[\mathrm{L}]=0.35 \mathrm{M}$, the excited-state equilibrium is not fully displaced towards the formation of ML*. However, for an infinite value of $[\mathrm{L}],\left(-1 / \Lambda_{2}\right)$ is equal to $\lambda_{2}^{-1}$ whatever the value of $K^{*}$. Again, this is in line with the fact that $\lambda_{2}^{-1}$ is an experimental parameter.

Next, the evolution of the intensities $J_{i}^{\mathrm{I}}$ associated to the emission spectra of $\mathrm{M}^{*}$ and $\mathrm{ML}^{*}$ as a function of [L] have been examined for the uranium case. Values for the three regimes are shown for $K^{*}=50 \mathrm{M}$ (Fig. 7) and $K^{*}=10^{4} \mathrm{M}$ (Fig. 8). This last value has been chosen to examine the impact of $K^{*}$ on the observed speciation. The curves represent the results that would be expected from a typical TRLFS experiment: they do not represent the speciation of $\mathrm{M}^{*}$ and $\mathrm{ML}^{*}$ but the observed fluorescence intensities, i.e. the speciation weighted by the $R_{\text {fluo }}$ value. Therefore, equal contributions of $\mathrm{M}^{*}$ and $\mathrm{ML}^{*}$ are obtained for a ratio $J_{1}^{\mathrm{I}} / J_{2}^{\mathrm{I}}$ equal to $17 / 83$. Whatever the value of $K^{*}$ (either 50 or $10^{4} \mathrm{M}$ ), at low $k_{1}$ values (regime $\mathrm{A}$ ), such a ratio is obtained for $[\mathrm{L}] \approx 7 \times 10^{-4} \mathrm{M}$ which actually corresponds to $K_{\text {app }}=[\mathrm{ML}] /([\mathrm{M}] \times[\mathrm{L}])=[\mathrm{L}]^{-1}$ : the photochemical processes are not rapid enough to have a significant influence within the lifetime of $\mathrm{M}^{*}$ and $\mathrm{ML}^{*}$, thus the speciation that is observed is that of the ground-state, as already explained above. On the contrary, if the photochemical processes are important (high $k_{1}$ values, regime C), the speciation is shifted towards higher [L] values for $K^{*}=50 \mathrm{M}$ and towards lower [L] values for $K^{*}=10^{4} \mathrm{M}$. The speciation that governs the emission spectra in regime $\mathrm{C}$ is $K^{*}(\alpha / \beta)\left(\tau_{1} / \tau_{2}\right)$ (see Eq. (13)). Hence, the lower the $K^{*}$ value, the higher [L] required for equal contributions of the two emitting species. In the case of europium, due to the similar values of $K$ and $(\alpha / \beta)\left(\tau_{1} / \tau_{2}\right) K^{*}$ chosen for the simulation, no shift is visible for increasing $k_{1}$ values (data not shown). The shift observed in Figs. 7, 8 clearly shows that the $K_{\text {app }}$ value derived with model (II) does not equal $K$, otherwise the speciation would not depend on $k_{1}\left(\right.$ or $\left.K^{*}\right)$.

For two uranium cases $\left(K^{*}=50 \mathrm{M}\right.$ or $\left.K^{*}=10^{4} \mathrm{M}\right)$ the calculated speciation (in terms of $J_{i}^{\mathrm{I}}$ see, e.g., Fig. 7) accord-

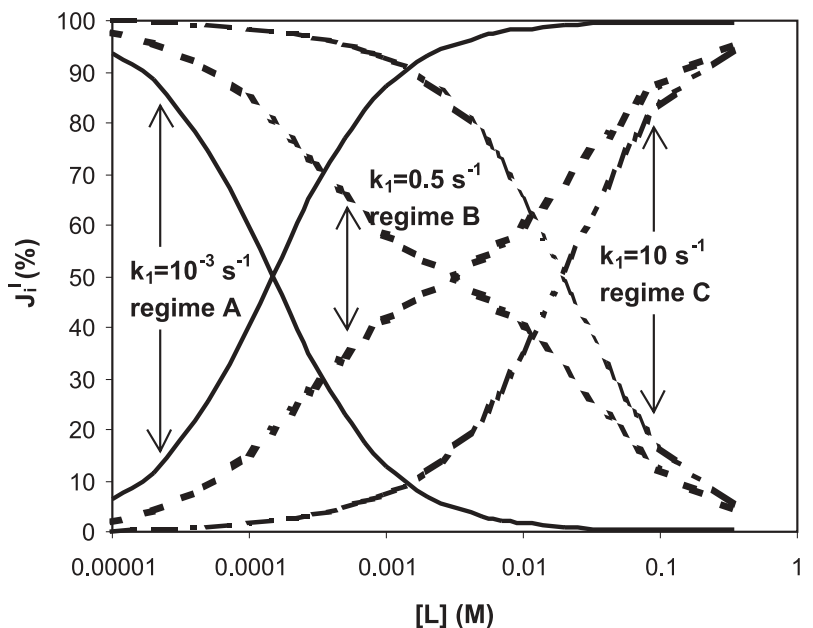

Fig. 7. Variations of $J_{i}^{\mathrm{I}}(\%)$ as a function of [L] for three values of $k_{1}$ and a fixed value $K^{*}=50 \mathrm{M}$ for the uranium simulation case.

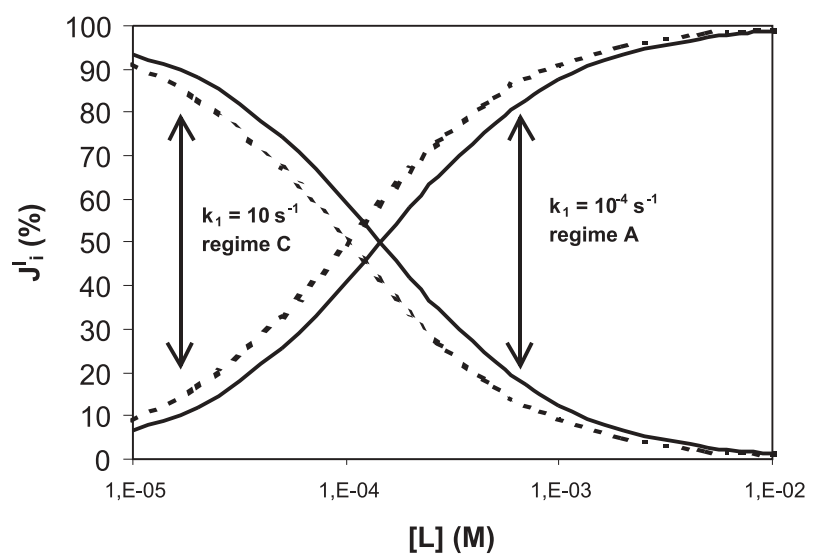

Fig. 8. Variations of $J_{i}^{\mathrm{I}}(\%)$ as a function of [L] for two values of $k_{1}$ and a fixed value $K^{*}=5 \times 10^{4} \mathrm{M}$ for the uranium simulation case.

ing to scheme (I) is fitted by $\chi^{2}$ minimization with Eq. $\left(12^{\prime}\right)$ (model II) in order to derive $K_{\text {app }}$. The resulting values are displayed in Fig. 9 along with the $K_{\text {app }}$ values for high (Eq. (13)) and low $\left(K_{\text {app }} \approx K\right)$ photochemical reaction rates. The $K_{\text {app }}$ values obtained from the fitting procedure vary within these respective limits. Thus, Eq. (13) corresponds to the limiting $K_{\text {app }}$ value for high rates $k_{1}$ (regime C) which confirms the qualitative arguments presented in Sect. 3.3. In regime $\mathrm{A}$ and $\mathrm{C}$, the $\chi^{2}$ values are excellent (below 0.001 ), which demonstrates that model (II) is a good approximation of scheme (I) for these two regimes. For regime $\mathrm{B}$, the $\chi^{2}$ values are significantly higher (up to 0.03 , which means that the calculated $J_{i}^{\mathrm{II}}$ values differ by $3 \%$ in average from the $J_{i}^{\mathrm{I}}$ value). Such a difference is not acceptable because the $J_{i}^{1}$ values arise from a calculation, not from scattered experimental values. Thus, in regime B, model II cannot be considered a good approximation of scheme I.

For the europium case, since $K^{*} \approx K$ and $(\alpha / \beta)\left(\tau_{1} / \tau_{2}\right)$ $\approx 1$, no significant difference is observed between the result from Eq. (13) and the expression $K_{\text {app }} \approx K$ (data not shown).

Finally, scheme (I) can also be confronted with model (II) with respect to the lifetime expressions. In regime A, as previously shown for the emission spectra, model (II) is a very good approximation of scheme (I). In regime B, the approximation with model (II) is not valid as the two lifetimes 


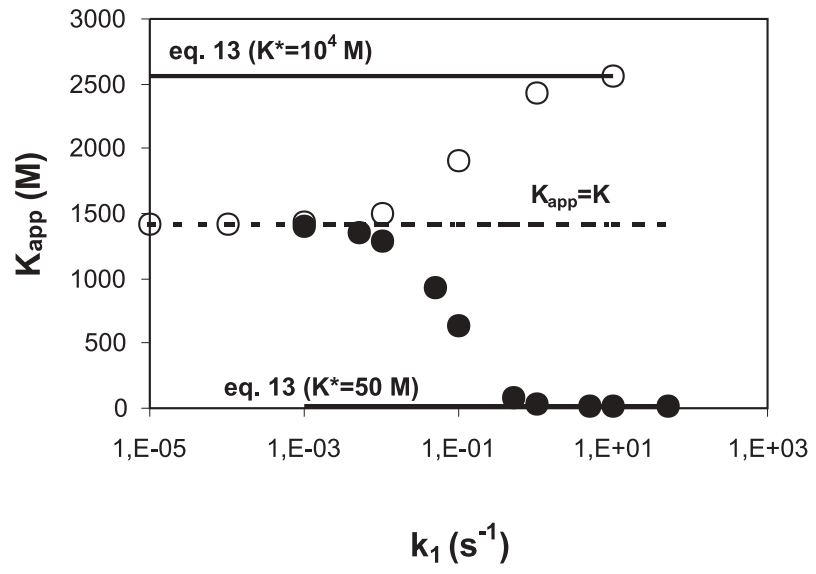

Fig. 9. Fitted values of $K_{\text {app }}$ as a function of $k_{1}$ with the values of Table 1 for the uranium simulation case. (O): $K^{*}=10^{4} \mathrm{M}$; $(\bullet)$ : $K^{*}=50 \mathrm{M}$. Solid lines: Values derived from Eq. (13) for $K^{*}=10^{4} \mathrm{M}$ or $K^{*}=50 \mathrm{M}$. Dotted line: $K_{\text {app }}=K$ (see text).

$\left(-1 / \Lambda_{1}\right)$ and $\left(-1 / \Lambda_{2}\right)$ are varying considerably as a function of [L] (see Figs. 3-6), while model (II) predicts constant $\lambda_{1}^{-1}$ and $\lambda_{2}^{-1}$ values. In regime $\mathrm{C}$, scheme (I) leads to a monoexponential behaviour of the decay spectra, while model (II) implies a bi-exponential behaviour. Therefore, an approximation of the lifetime values through model (II) appears difficult. However, an expression has been suggested [41] where the biexponential behaviour is hidden in a single lifetime $\lambda_{\text {obs }}^{-1}$ obtained from a monexponential fit of the decay spectrum. This simplified equation is:

$$
\lambda_{\text {obs }}=\frac{[\mathrm{M}]}{[\mathrm{M}]+[\mathrm{ML}]} \lambda_{1}+\frac{[\mathrm{ML}]}{[\mathrm{M}]+[\mathrm{ML}]} \lambda_{2},
$$

where $[\mathrm{M}]$ and $[\mathrm{ML}]$ are the equilibrium concentrations of the two species. Values obtained from Eq. (16) are compared (see Fig. 10) to the ones from Eq. (5) for two uranium cases $\left(K^{*}=50 \mathrm{M}\right.$ and $K^{*}=10^{4} \mathrm{M}$ in regime $\left.\mathrm{C}\right)$. For high $K^{*}$ values, the mixing of the two emitting species is more efficient than expected through Eq. (16), while the mixing is less efficient for low $K^{*}$ values. Again, this is due to the fact that the speciation that governs the lifetime values is $K^{*}$ and not $K$, as in Eq. (16).

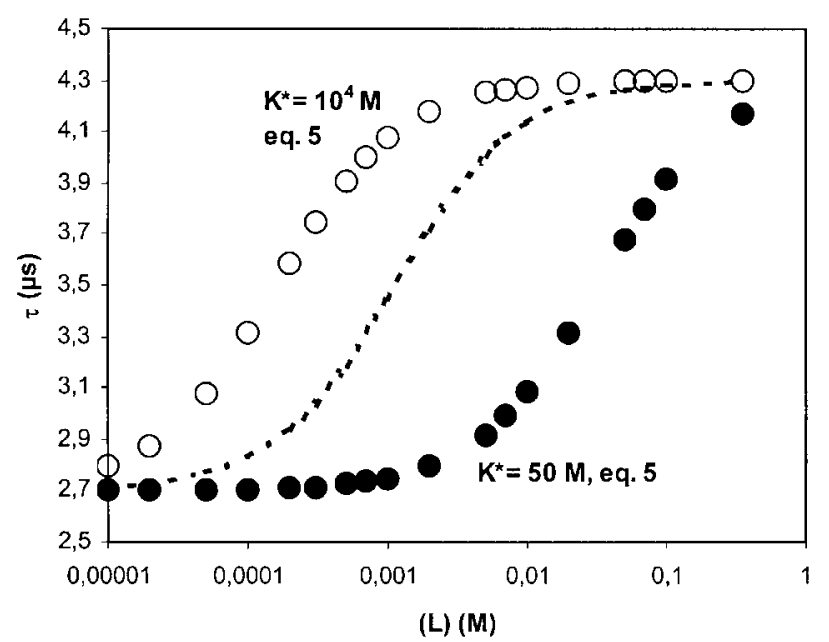

Fig. 10. Variations of the lifetime as a function of $[\mathrm{L}]$ for the uranium case: (O): values of Table 1 and $K^{*}=10^{4} \mathrm{M}$, regime C. $(\bullet)$ : values of Table 1 and $K^{*}=50 \mathrm{M}$, regime C. (---): Eq. (16).
For the europium case, since $K^{*} \approx K$, the lifetime variations derived from Eq. (16) are in good agreement with the values calculated with scheme (I). However, if $K^{*}$ is very different from $K$ (keeping $\alpha / \beta$ and $\lambda_{i}$ as indicated in Table 1$)$, the discrepancy clearly appears as well.

\section{Discussion}

In a first step, literature data on radiochemical systems studied by TRLFS are collected and tentatively associated to one of the three regimes of interest (A, B or C) described above. This review is by no means complete. Inorganic ligands have deliberately been favored and complex systems such as natural ground waters and humic or fulvic complexing agents have not been considered. As stressed above, the shape of the decay spectra (mono vs. multiexponential) yields important information on the regime (A, B or C) that is valid for a given system. In the publications examined below, the type of fitting that was used (mono or multi exponential) is usually indicated or the shape of the decay spectra is mentioned. In some cases, decay spectra are also displayed.

For uranium systems with ligands such as arsenate [22] or silicic acid [21] multiexponential decay spectra are observed. These two systems correspond therefore to either regimes A or B. Multiexponential behaviour was also found for hydrolysed uranyl ions [17, 19, 57]. In the study of [19], the two lifetimes are independent of $\mathrm{pH}$ which is strongly in favor of an attribution to regime A. In [20], however, a monoexponential behaviour is reported for this system. Thus, it is concluded that photochemical processes are fast, which would correspond to regime $\mathrm{C}$. For the ligand $\mathrm{SO}_{4}{ }^{2-}$, the reported spectra are multiexponential [18] (regime A or B). For fluoride ions, the situation appears somewhat more controversial. [15] concludes that photochemical processes are very fast and that the values of $K^{*}$ (for the $1: 1$ and $1: 2$ complex) are different from those of the ground state (one being smaller, the other one larger). In contrast, the decay was found to be biexponential when the $\mathrm{UO}_{2}{ }^{2+}$ and the $1: 1$ complex are present, while the decay becomes monoexponential when the $1: 1$ and $1: 2$ complex exist in solution [58]. Multiexponential decays are reported in [59], whatever the species present in solution. Finally, a recent round-robin test on these systems ascribes multiexponential behaviour to $\mathrm{UO}_{2}{ }^{2+} / \mathrm{OH}^{-}, \mathrm{UO}_{2}{ }^{2+} / \mathrm{SO}_{4}{ }^{2-}$ and $\mathrm{UO}_{2}{ }^{2+} / \mathrm{F}^{-}[60]$.

In the case of europium, the two previous studies by Horrocks and Ermolaev [41,42] already showed that systems corresponding to either regimes $\mathrm{A}, \mathrm{B}$ or $\mathrm{C}$ exist. For ligands of similar structures (such as malonate, succinate, glutarate...), or depending on the stoiechiometry, monoexponential as well as biexponential decays are reported [30,61].

An actinide element often used for fluorescence studies is curium. Upon complexation with $\mathrm{F}^{-}[23], \mathrm{CO}_{3}{ }^{2-}[24,26,27]$, $\mathrm{SO}_{4}{ }^{2-}$ [28], $\mathrm{Cl}^{-}$[44] and $\mathrm{OH}^{-}$[29], the decays are exclusively monoexponential which corresponds to regime $\mathrm{C}$. The existence of fast photochemical processes is assumed in $[23,28]$. To our knowledge, in solution, the only curium systems with multiexponential decays are the ones with organic ligands $[62,63]$ and the mixed system $\mathrm{Cm} / \mathrm{Am}$ with 
humic acids. In this case, the two lifetimes are reported to vary as a function of $\mathrm{pH}$ [64] which would correspond to regime A or B. Note that a bi-exponential decay is described for $\mathrm{Cm}$ embedded in a solid calcite lattice [65], which does not compare well with the aqueous solutions discussed in this work (in particular, no diffusion of the species is forseen in the lattice).

From the above examples the following conclusions can be drawn:

i) Uranyl systems correspond to regime A or B, with the possible exception of the $\mathrm{F}^{-}$ligand.

ii) For europium, systems belonging to either one of the three regimes have been reported.

iii) Curium systems fall within regime $\mathrm{C}$ for all inorganic ligands investigated so far.

Depending on the element of interest, different relationships result between the $K_{\text {app }}$ values determined by TRLFS and the values of $K$.

For the uranium systems (with the possible exception of $\mathrm{F}^{-}$), the value of $K_{\text {app }}$, which is determined by TRLFS and model (II), is in fact equal to $\mathrm{K}$ (see Sect. 3.1). This is confirmed in the case of the $\mathrm{UO}_{2}{ }^{2+} / \mathrm{SO}_{4}{ }^{2-}$ system [18] by the very good agreement between the equilibrium constant as recommended by NEA and the value from TRLFS.

In the case of europium complexation, depending on the type of ligand, TRLFS experiments give access directly to $K$ (regime A) or cannot be used to derive $K$ (regime $\mathrm{B}$ ). For a system that falls within regime $\mathrm{C}$, the determination of $K$ is feasible, provided that the term $(\alpha / \beta)\left(\tau_{1} / \tau_{2}\right)$ is measured or known: In fact, for a few Eu(III) systems the $K_{\text {app }}$ value derived by TRLFS has been compared to the value derived by other techniques. It happens that $\tau_{2}$ values are below $140 \mu$ s $[46,61]$ while the $\tau_{1} \approx 110 \mu$ s corresponds to the lifetime of the free europium ion $[34,66,67]$. This yields $\tau_{1} / \tau_{2} \approx 1-1.3$. In addition, the strong shielding of the $4 f$ electrons in lanthanide elements should result in small variations of the absorption coefficient upon complexation [6870 ], which would give $\alpha / \beta \approx 1$. Hence, the correction term $(\alpha / \beta)\left(\tau_{1} / \tau_{2}\right)$ is close to unity. This would explain the agreement obtained between equilibrium constants measured by TRLFS and other techniques [46].

For the systems composed of curium and inorganic ligands, on the other hand, the $K_{\text {app }}$ values derived by TRLFS are related to $K^{*}$ rather than to $K$ (see Eq. (13)). To our knowledge, no simple relationship between $K^{*}$ and $K$ has been derived for $5 f$ elements and the assumption of $K^{*} \approx K$ relies on the similarities in the chemistry of $4 f$ and $5 f$ elements, a question that does not seems to be straightforward [71]. However, a difference between $K$ and $K^{*}$ might be important, as it can be very large in some systems, e.g., $K^{*}=10^{-2.8}$ and $K=10^{-9.5}$ for deprotonation of 2-naphtol [51]. In addition, even with the assumption of $K^{*} \approx K$, the ratio $(\alpha / \beta)$ is needed to infer $K$ from $K_{\text {app }}$. This value is not easy to determine, because of the large amount of $\mathrm{Cm}$ required for an absorption measurement. In conclusion, for $\mathrm{Cm}$ systems several questions are left open concerning the relationship between $K_{\text {app }}, K^{*}$ and $K$. This point is of a certain relevance for calculations of the migration of curium in the environment [72]. One may also wonder why inorganic ligands lead to regime A with U(VI) and to regime $\mathrm{C}$ with $\mathrm{Cm}$.

\section{Conclusion and perspectives}

Although the physical reasoning on which Eq. (13) is based is confirmed by the simulations (see Fig. 9), its experimental verification is highly desirable. To this end, a system should be chosen where $K^{*}$ is well known, since, in principle, $(\alpha / \beta)\left(\tau_{1} / \tau_{2}\right)$ can be measured independently. This implies that an experimental verification should be performed for lanthanide systems, for which the assumption $K^{*} \approx K$ is supported by experimental evidence.

The ratio of the absorption coefficients $(\alpha / \beta)$ depends sensitively on the excitation wavelength. For europium systems, an excitation at $394 \mathrm{~nm}$ or $578 \mathrm{~nm}$ is known to lead to $(\alpha / \beta) \approx 1$. A pronounced difference between $\alpha$ and $\beta$ can be obtained by use of the antenna effect for lanthanide complexes [39,40,73]: At excitation wavelengths in the near-UV region the absorption of the free ion is negligible $(\alpha \approx 0)$ while the complex is excited after photoabsorption by the ligand and subsequent energy transfer to the metal center $(\beta \gg \alpha)$. A TRLFS test experiment should therefore be performed for the same system (europium and a ligand suitable for the antenna effect) at two different excitation wavelengths, while keeping all other parameters (temperature, concentration ratio of ligand to europium ...) constant. It is thus expected that the $K_{\text {app }}$ value obtained at the two excitation wavelengths by use of model (II) will differ significantly. Experiments of this kind performed in our laboratory confirm this hypothesis and will be published separately.

The choice of the proper system for studying the role of $\tau_{1} / \tau_{2}$ is more difficult. The lifetimes are intrinsic properties of the excited systems and cannot be modified by external factors. A system for a TRLFS test experiment should have considerably different $\tau_{1}$ and $\tau_{2}$ values. The derived $K_{\text {app }}$ value would then be compared to the one obtained with other techniques, such as potentiometry or spectrophotometry. The complexing agent should not be too strong. The resulting high $K_{\text {app }}$ value would make the comparison of the various methods ( $\left.\Delta K_{\text {app }}\right)$ difficult due to small $\Delta K_{\text {app }} / K_{\text {app }}$ ratios. The difference induced by the factor $\tau_{1} / \tau_{2}$ must exceed the uncertainties of $K_{\text {app }}$ for the experiment to be conclusive. This implies roughly $\left(\tau_{1} / \tau_{2}\right)<1 / 8$. For europium $\left(\tau_{1}=110 \mu \mathrm{s}\right)$ systems, however, ligands with $\tau_{2}>800 \mu \mathrm{s}$ (mainly macrocyclic ligands $[39,74]$ ) are usually very efficient complexing agents with complexation constants in the range of $10^{12}$ or more $[75,76]$. These values are too high for the confrontation of the different methods $\left(\Delta K_{\text {app }} / K_{\text {app }}<\right.$ $10^{-10}$ ). At present, no ligand suitable for such a comparative experiment has been defined.

To summarize, focussing on lanthanide and actinide systems, the interplay between ground and excited state reactions in laser fluorescence experiments has been studied. Simulations were performed as a function of the reaction rates in the excited state for $\mathrm{UO}_{2}{ }^{2+}$ and $\mathrm{Eu}^{3+}$ complexation as examples. Information on ground-state equilibrium constants can be obtained, if the photochemical reaction rates are either slow or fast with respect to the lifetimes of the excited species: In the case of slow reactions, the measured 
equilibrium constant corresponds to the $K$ value. For fast reactions the measured value corresponds to Eq. (13). Ground state equilibrium constants $K$ can be inferred if the absorption coefficients of the ground state species and the lifetimes of the excited states are known. In addition, the relationship between $K$ and $K^{*}$ must be known which is generally the case for lanthanide systems $\left(K \approx K^{*}\right)$. In the case of actinide elements more information is desirable.

Acknowledgment. Stimulating discussions with Dr. Gilles Montavon and financial support of the groupement de recherches PRACTIS are gratefully acknowledged.

\section{References}

1. Fuger, J.: Radiochim. Acta 58, 81 (1992).

2. Silva, R., Nitsche, H.: Radiochim. Acta 70/71, 377 (1995).

3. Palmer, D. A., Nguyen-Trung, C.: J. Solution Chem. 24, 1281 (1995).

4. Hrnecek, E., Irlweck, K.: Radiochim. Acta 87, 29 (1999).

5. Jyothi, A., Rao, G. N.: 37, 431 (1990).

6. Jensen, M. P., Choppin, G. R.: Radiochim. Acta 82, 83 (1998).

7. Dai, S., Burleigh, M. C., Simonson, J. M., Mesmer, R. E., Xue, Z. L.: Radiochim. Acta 81, 195 (1998).

8. Meinrath, G.: J. Alloys Compd. 275/277, 777 (1998).

9. Moulin, C., Charron, N., Plancque, G., Virelizier, H.: Appl. Spec. 54, 843 (2000).

10. Moulin, C., Amekraz, B., Hubert, S., Moulin, V.: Analytica Chimica Acta 441, 269 (2001).

11. Moulin, C., Beaucaire, C., Decambox, P., Mauchien, P.: Anal. Chim. Acta 238, 291 (1990).

12. Moulin, C., Decambox, P., Mauchien, P.: Anal. Chim. Acta 254, 145 (1991).

13. Moulin, C., Laszak, I., Moulin, V., Tondre, C.: Appl. Spectrosc. 52, 528 (1998).

14. Decambox, P., Mauchien, P., Moulin, C.: Radiochim. Acta 48, 23 (1989).

15. Beitz, J. V., Williams, C.: J. Alloys Compd. 250, 375 (1997).

16. Brendler, V., Geipel, G., Bernhard, G., Nitsche, H.: Radiochim. Acta 74, 75 (1996).

17. Eliet, V., Grenthe, I., Bidoglio, G.: Appl. Spectrosc. 54, 99 (2000).

18. Geipel, G., Brachmann, A., Brendler, V., Bernhard, G., Nitsche, H.: Radiochim. Acta 75, 199 (1996).

19. Lopez, M., Birch, D. J. S.: Chem. Phys. Lett. 268, 125 (1997).

20. Meinrath, G., Lis, S., Stryla, Z., Noubactep, C.: J. Alloys Compd. 300/301, 107 (2000).

21. Moll, H., Geipel, G., Brendler, V., Bernhard, G., Nitsche, H.: J. Alloys Compd. 271/273, 765 (1998).

22. Rutsch, M., Geipel, G., Brendler, V., Bernhard, G., Nitsche, H.: Radiochim. Acta 86, 135 (1999).

23. Aas, W., Steinle, E., Fanghänel, T., Kim, J. I.: Radiochim. Acta 84, 85 (1999).

24. Beitz, J. V.: Radiochim. Acta 52, 35 (1991).

25. Fanghänel, T., Kim, J. I., Klenze, R., Kato, Y.: J. Alloys Compd. 225, 308 (1995).

26. Fanghänel, T., Weger, H., Konnecke, T., Neck, V., Paviet-Hartmann, P., Steinle, E., Kim, J. I.: Radiochim. Acta 82, 47 (1998).

27. Aime, S., Barge, A., Botta, M., de Sousa, A. S., Parker, D.: Angew. Chem. Int. Ed. 37, 2673 (1998).

28. Paviet, P., Fanghänel, T., Klenze, R., Kim, J. I.: Radiochim. Acta 74, 99 (1996).

29. Wimmer, H., Klenze, R., Kim, J. I.: Radiochim. Acta 56, 79 (1992).

30. Barthelemy, P. P., Choppin, G. R.: Inorg. Chem. 28, 3354 (1989).

31. Bidoglio, G., Grenthe, I., Qi, P., Robouch, P., Omenetto, N.: Talanta 38, 999 (1991).

32. Choppin, G. R., Peterman, D. R.: Coord. Chem. Rev. 174, 283 (1998).

33. Kim, J. I., Klenze, R., Wimmer, H., Runde, W., Hauser, W.: J. Alloys Compd. 213, 333 (1994)

34. Kimura, T., Kato, Y.: J. Alloys Compd. 278, 92 (1998).

35. Lis, S., But, S.: J. Alloys Compd. 300/301, 370 (2000).
36. Moulin, C., Wei, J., Van Iseghem, P., Laszak, I., Plancque, G., Moulin, V.: Anal. Chim. Acta 396, 253 (1999).

37. Shin, H., Choppin, G. R.: Radiochim. Acta 86, 167 (1999).

38. Takahashi, Y., Kimura, T., Kato, Y., Minai, Y., Makide, Y., Tominaga, T.: J. Radioanal. Nucl. Chem. 239, 335 (1999).

39. Parker, D., Williams, J.: J. Chem. Soc., Dalton Trans. 3613 (1996).

40. Richardson, F.: Chem. Rev. 82, 541 (1982).

41. Horrocks, W. d. J., Arkle, V. K., Liotta, F. J., Sudnick, D. R.: J. Am. Chem. Soc. 105, 3455 (1983).

42. Ermolaev, V. L., Gruzdev, V. P.: Inorg. Chim. Acta 95, 179 (1984).

43. Kato, Y., Meinrath, G., Kimura, T., Zenko, Y.: Radiochim. Acta 64, 107 (1994)

44. Fanghänel, T., Kim, J. I.: J. Alloys Compd. 271/273, 728 (1998).

45. Couston, L., Pouyat, D., Moulin, C., Decambox, P.: Appl. Spectrosc. 49, 349 (1995).

46. Wang, Z. M., van de Burgt, L. J., Choppin, G. R.: Inorg. Chim. Acta 293, 167 (1999).

47. Agmon, N., Gopich, I. V.: Chem. Phys. Lett. 302, 399 (1999).

48. Berberan-Santos, M. N., Farinha, J. P. S., Martinho, J. M. G.: Chem. Phys. 260, 401 (2000).

49. Sienicki, K., Durocher, G.: J. Photochem. Photobiol. A 63, 279 (1992).

50. Molski, A., Boens, N.: J. Phys. Chem. A 101, 5124 (1997).

51. Laws, W. R., Brand, L.: J. Phys. Chem. 83, 795 (1979).

52. Molski, A., Naumann, W.: J. Chem. Phys. 103, 10050 (1995).

53. Al-Soufi, W., Novo, M., Mosquera, M.: Appl. Spectrosc. 55, 630 (2001).

54. Beechem, J. M., Ameloot, M., Brand, L.: Chem. Phys. Lett. 120 466 (1985)

55. Argaman, R., Molotsky, T., Huppert, D.: J. Phys. Chem. A 104, 7934 (2000).

56. Grenthe, I.: Chemical Thermodynamics of Uranium. NorthHolland, Amsterdam (1992).

57. Moulin, C., Decambox, P., Moulin, V., Decaillon, J. G.: Anal. Chem. 67, 348 (1995).

58. Moriyasu, M., Yokoyama, Y., Ideka, S.: J. Inorg. Nucl. Chem. 39 2199 (1977).

59. Fazekas, Z., Yamamura, T., Tomiyasu, H.: J. Alloys Compd 271/273, 756 (1998).

60. Billard, I., Ansoborlo, E., Apperson, K., Arpigny, S., Azehna, A. E., Birch, D., Bros, P., Burrows, H., Choppin, G. R., Couston, L., Dubois, V., Fanghänel, T., Geipel, G., Hubert, S., Kim, J. I., Kimura, T., Klenze, R., Kronenberg, A., Kumke, M., Lagarde, G., Lamarque, G., Lis, S., Madic, C., Meinrath, G., Moulin, C., Nagaishi, R., Parker, D., Plancque, G., Scherbaum, F., Simoni, E., Sinkov, S., Viallesoubranne, C.: Appl. Spectrosc. (2003) in press.

61. Albin, M., Farber, G. K., Horrocks, W. d. J.: Inorg. Chem. 23, 1648 (1984).

62. Panak, P., Klenze, R., Kim, J. I., Wimmer, H.: J. Alloys Compd. 225, 261 (1995).

63. Klenze, R.: private communication (2001).

64. Morgenstern, M., Klenze, R., Kim, J. I.: Radiochim. Acta 88, 7 (2000).

65. Stumpf, T., Fanghänel, T.: J. Colloid Interface Sci. 249, 119 (2002).

66. Moulin, C., Larpent, C., Gazeau, D.: Analytica Chimica Acta 378, 47 (1999).

67. Lis, S., Choppin, G. R.: Mat. Chem. Phys. 31, 159 (1992).

68. Giroux, S., Rubini, P., Henry, B., Aury, S.: Polyhedron 19, 1567 (2000).

69. Clarkson, I. M., Beeby, A., Bruce, J. I., Govenloch, L. J., Lowe, M. P., Mathieu, C. E., Parker, D., Senanayake, K.: New J. Chem. 24, 377 (2000).

70. Bryden, C. C., Reilley, C. N.: Anal. Chem. 54, 610 (1982).

71. Choppin, G. R.: J. Less-Common Met. 93, 323 (1983).

72. Nitzsche, O., Meinrath, G., Merkel, B.: J. Contam. Hydrol. 44, $223(2000)$

73. Latva, M., Takalo, H., Mukkala, V. M., Matachescu, C., RodriguezUbis, J. C., Kankare, J.: J. Luminescence 75, 149 (1997).

74. François, N.: Thèse. Université Henri Poincaré (1999).

75. Wu, S., Horrocks, W. d. J.: J. Chem. Soc., Dalton Trans 1497 (1997).

76. Wu, S., Horrocks, W. d. J.: Anal. Chem. 68, 394 (1996). 